GEOPHYSICAL RESEARCH LETTERS, VOL. 12, NO. 6, PAGES 345-348, JUNE 1985

\title{
AFTERSHOCK AREA EXPANSION AND MECHANICAL HETEROGENEITY OF FAULT ZONE WITHIN SUBDUCTION ZONES
}

\author{
Fumiko Tajima \\ Institute for Geophysics, The University of Texas at Austin, Austin, TX 78751 \\ Hiroo Kanamori
}

Seismological Laboratory, California Institute of Technology, Pasadena, CA 91125

Abstract. We investigate global variations in the pattern of aftershock area expansion associated with large subduction zone earthquakes. The expansion of aftershock areas with time is relatively small in the subduction zones of Alaska, the Aleutians, Mexico, and parts of the Kuriles and South America. These subduction zones are interpreted to be characterized by moderate to strong interplate coupling. In contrast, the extent of aftershock expansion is greater for events within the subduction zones of northeast Japan and western and south Pacific where interplate coupling is inferred to be weak. These results are interpreted in terms of an asperity model where a fault zone is represented by a distribution of strong spots (asperities) and weaker zones. The immediate aftershock area is assumed to extend over an area occupied by asperities, and the subsequent expansion to occur into the surrounding weaker zones. If large asperities abut each other on a fault plane, interplate coupling is strong and little expansion of aftershock area occurs. Smaller and more sparsely distributed asperities cause weak interplate coupling and significant expansion of aftershock area. Small and densely distributed asperities result in moderate interplate coupling and little aftershock expansion.

\section{Introduction}

The importance of fault-zone heterogeneity has been repeatedly emphasized in various aspects of earthquake seismology: seismicity patterns, source rupture processes, generation of strong ground motions, etc. Although the mechanism of aftershock occurrence has not been fully understood yet, the spatial distribution of aftershocks and its expansion pattern seem to provide clues to the mechanical property of the source region. Here we attempt to infer global variations of fault-zone heterogeneity along subduction zones by examining the expansion of aftershock areas resulting from large subduction zone earthquakes.

Mogi $(1968,1969)$ noted significant variations in the expansion patterns of aftershock areas of 10 large $(M \geq 8)$ earthquakes. He noted that in the Tokachi-Oki region (the off-shore of southeastern Hokkaido), the aftershock area of large earthquakes usually shows significant expansion, the 1968 earthquake $\left(M_{w}=8.2\right)$ being one of the typical

Copyright 1985 by the American Geophysical Union.

Paper number 5L6534.

0094-8276/85/005L-6534\$03.00
TABLE 1. List of Earthquakes

\begin{tabular}{rrrrlcl}
\hline No. & Year & Mon & Day & Area & $\mathbf{M}_{\mathbf{w}}$ & $\mathbf{M}_{\mathbf{s}}$ \\
\hline 1$)$ & 1963 & 10 & 13 & Kurile & 8.5 & 8.1 \\
$2)$ & 1964 & 3 & 28 & Alaska & 9.2 & 8.4 \\
$4)$ & 1965 & 2 & 4 & Rat Is. & 8.7 & 7.75 \\
$5)$ & 1965 & 8 & 23 & Oaxaca, Mexico & $7.7 \mathrm{~A}$ & 7.6 \\
$6)$ & 1966 & 3 & 12 & Taiwan & 7.4 & 7.6 \\
$7)$ & 1966 & 10 & 17 & Peru & 8.1 & 7.8 \\
$8)$ & 1966 & 12 & 28 & Chile & 7.8 & 7.7 \\
$9)$ & 1966 & 12 & 31 & Santa Cruz Is. & $8.0 \mathrm{~A}$ & 7.9 \\
$10)$ & 1968 & 5 & 16 & Tokachi-Oki & 8.2 & 8.1 \\
$11)$ & 1968 & 8 & 10 & Molucca Sea & & 7.6 \\
$13)$ & 1969 & 8 & 11 & Kurile & 8.2 & 7.8 \\
$16)$ & 1970 & 12 & 10 & Peru & & 7.6 \\
$18)$ & +1971 & 7 & 14 & Solomon & $8.0 \mathrm{~A}$ & 7.8 \\
$19)$ & +1971 & 7 & 26 & Solomon & $8.1 \mathrm{~A}$ & 7.7 \\
$20)$ & 1971 & 12 & 15 & Kamchatka & & 7.5 \\
$22)$ & 1973 & 6 & 17 & Nemuro & 7.8 & 7.7 \\
$23)$ & 1974 & 10 & 3 & Peru & 8.1 & 7.6 \\
$25)$ & 1975 & 5 & 10 & Southern Chile & & 7.6 \\
$27)$ & +1975 & 7 & 20 & Solomon Is. & $8.0 \mathrm{~A}$ & 7.6 \\
$28)$ & +1975 & 7 & 20 & Solomon Is. & & 7.5 \\
$30)$ & 1975 & 12 & 26 & Tonga & & 7.5 \\
$31)$ & +1976 & 1 & 14 & Kermadec & & 7.7 \\
$32)$ & +1976 & 1 & 14 & Kermadec & & 7.9 \\
$34)$ & 1976 & 8 & 16 & Mindanao & 8.1 & 7.8 \\
$37)$ & 1978 & 3 & 24 & Kurile & & 7.6 \\
$38)$ & 1978 & 6 & 12 & Miyagi-Oki & 7.4 & 7.5 \\
$39)$ & 1978 & 11 & 29 & Oaxaca, Mexico & 7.6 & 7.9 \\
$40)$ & 1979 & 3 & 14 & Petatlan, Mexico & & 7.6 \\
$41)$ & 1979 & 9 & 12 & New Guinea & & 7.7 \\
$42)$ & 1979 & 12 & 12 & Colombia & 7.9 & 7.6 \\
$43)$ & +1980 & 7 & 8 & Santa Cruz Is. & 7.4 & 7.5 \\
$44)$ & +1980 & 7 & 17 & Santa Cruz Is. & 7.8 & 7.7 \\
$50)$ & 1972 & 1 & 23 & Santa Cruz Is. & & 7.1 \\
$51)$ & 1972 & 2 & 29 & Hachijo-Oki & & 7.1 \\
$53)$ & 1979 & 8 & 17 & New Hebrides & & 6.1 \\
$54)$ & 1980 & 10 & 25 & Loyalty Is. & 7.47 & 7.2 \\
\hline L4 & $0 f 32$ & 1 & & & & \\
\hline
\end{tabular}

List of 32 shallow large $\left(\mathrm{h} \leq 70 \mathrm{~km} ; \mathrm{M}_{\mathrm{s}} \geq 7.5\right)$ and 5 moderate $\left(6.1 \leq \mathrm{M}_{\mathrm{S}} \leq 7.2\right)$ subduction earthquakes which occurred from 1963 to 1980 . The plus mark $(+)$ indicates doublet.

examples. On the contrary, great earthquakes such as the 1964 Alaskan $\left(M_{w}=9.2\right)$ and the 1965 Rat Islands $\left(M_{w}=8.7\right)$ earthquakes did not show much expansion of the ${ }^{\mathrm{W}}$ aftershock area, especially lengthwise. These 


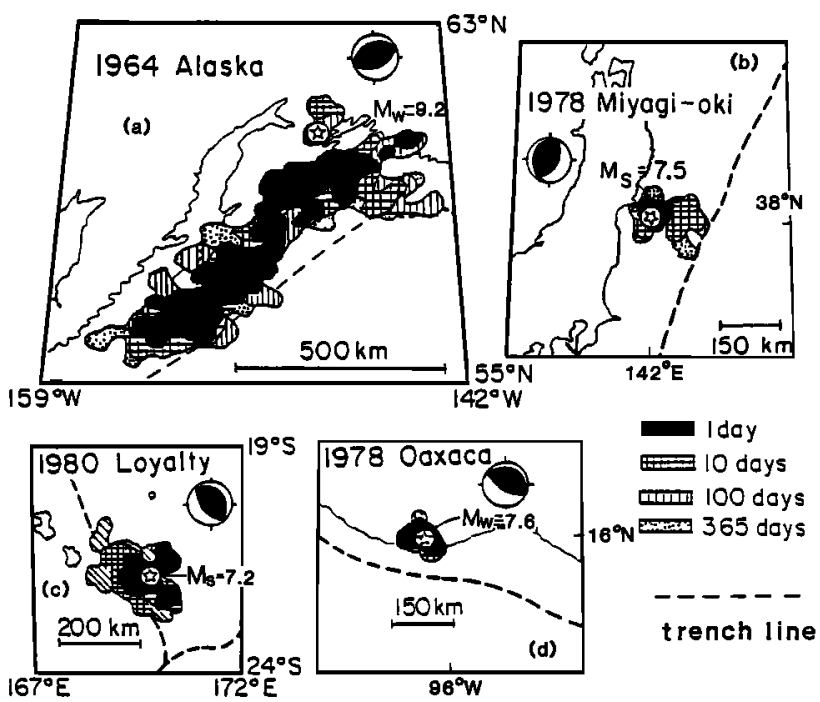

Fig. 1. The aftershock areas of the 1964 Alaskan, the 1978 Miyagi-Oki, the 1978 Oaxaca, and the 1980 Loyalty Is. earthquakes determined at four different times, one day, ten days, one hundred days, and one year after the main event. The 1980 Loyalty Is. earthquake sequence is examined up to the end of 1980 . The hatched area shows the 67 day aftershock area. The mechanism of the main shock is indicated by a stereographic projection of the lower focal hemisphere with the compressional quadrants darkened.

observations suggest that the aftershock area expansion pattern reflects the spatial variation of fault-zone properties.

Recently, Tajima and Kanamori $(1981,1985)$ developed a method to objectively define the aftershock area of large earthquakes. Using this method, Tajima and Kanamori studied the aftershock area expansion patterns of 44 large $\left(M_{s} \geq 7.5\right)$ and 5 moderate shallow earthquakes which occurred from 1963 to 1980 (see Table 1 for subduction events). Here we summarize the patterns and discuss their implications for fault-zone heterogeneities.

\section{Global Variation of Aftershock Area Expansion Patterns}

Our definition of an aftershock area is based upon the amount of energy released by aftershocks. To obtain a value for the aftershock area, the energy released by the aftershocks during a given time period is first spatially averaged and then contoured. On these contour plots each contour outlines an area within which the energy release from the aftershocks was above a given value. By our definition the "one-day aftershock area" is enclosed by the contour line corresponding to the energy release level of $10^{15.6} \mathrm{ergs} /\left(100 \mathrm{~km}^{2}\right.$. day $)$. This value was determined from the data for the 1964 Alaskan earthquake sequence. The 10-day, 100-day, and 1-year aftershock areas are similarly defined by contour lines corresponding to $10^{14.8}, 10^{14.0}$, and $10^{13.5} \mathrm{ergs} /\left(100 \mathrm{~km}^{2}\right.$.day), respectively. These three energy levels are derived from the energy level for the 1day aftershock area using Omori's (1894) law for the decrease of aftershock activity with time. We examine each aftershock sequence at four different times, one day, ten days, one hundred days, and one year after the main event using these energy levels. Aftershock areas defined at a later stage (e.g. one year) are sometimes obscured by the background seismicity in the vicinity of the mainshock. Therefore, we primarily use the expansion patterns up to 100 days in the present study.

Figure 1a shows the aftershock area of the 1964 Alaskan earthquake $\left(M_{w}=9.2\right)$ determined at four different times. The length of the aftershock area $(\mathrm{L} \sim 800 \mathrm{~km})$ determined on the first day remained essentially the same, while some lateral expansion was observed. The final width is about $200 \mathrm{~km}$ on the average. The 1965 Rat Islands earthquake showed a similar expansion pattern: the length ( $L \sim 600$ $\mathrm{km}$ ) determined on the first day changed little, but the width increased considerably by March 30,1965 , when a large normal-fault event occurred near the trench, and became about $250 \mathrm{~km}$ which is wider than observed for the 1964 Alaskan earthquake. The lengths of the aftershock areas of these earthquakes are about the same as the main shock rupture lengths determined from the radiation directivity of long-period surface waves (Kanamori, 1970; Wu and Kanamori, 1973), indicating that the aftershocks are mostly confined to the region of coseismic slip during the main shock. Ruff and Kanamori (1983) found for these same events that the rupture area determined from seismic body waves is considerably smaller than that from longperiod surface waves. They defined the area involved in body-wave radiation as the asperity. Similar results have been obtained for many other events (e.g. Lay and Kanamori, 1981; Vidale and Kanamori, 1983; Beck and Ruff, 1984; Schwartz and Ruff, 1984). The asperities are usually defined as areas on a fault plane which are stronger than the surrounding areas. In this work, we envision the asperity to be the rupture zone of the overall main shock, commonly defined by surface wave radiations.

In the Kuriles, the sizes of the main shocks are smaller than those in Alaska and the Aleutians. Many background events merge into the aftershock area in later periods $(\triangleright 100$ days). In this region the aftershock areas of adjacent earthquakes sometimes overlap each other. Relatively minor expansion of the aftershock area is a feature common to these earthquakes.

Complex expansion patterns are observed in the sequences of the 1968 Tokachi-Oki, the 1978 Miyagi-Oki (Figure 1b) and the 1972 Hachijo-Oki earthquakes. The aftershock areas were relatively small on the first day but expanded significantly. These expansion patterns indicate that the stress and the strength distribution in the source areas is highly heterogeneous possibly due to the complex tectonic settings in northeastern Japan.

In the southwestern Pacific subduction zones which include Ryukyu and the Philippine Sea, the expansion patterns are also complex. The aftershock activity is sometimes confined in a small area for the period less than 100 days, then expands into the surrounding area. This pattern indicates that the boundaries between the main shock rupture zone and the surrounding areas are relatively weak, and the stress change caused by the mainshock diffuses into the surrounding area after some time delay.

In the Solomon Islands region, the aftershock areas appear to expand significantly due to the occurrence of doublets (Lay and Kanamori, 1980). However, after the second event of the doublet, the aftershock areas do not 


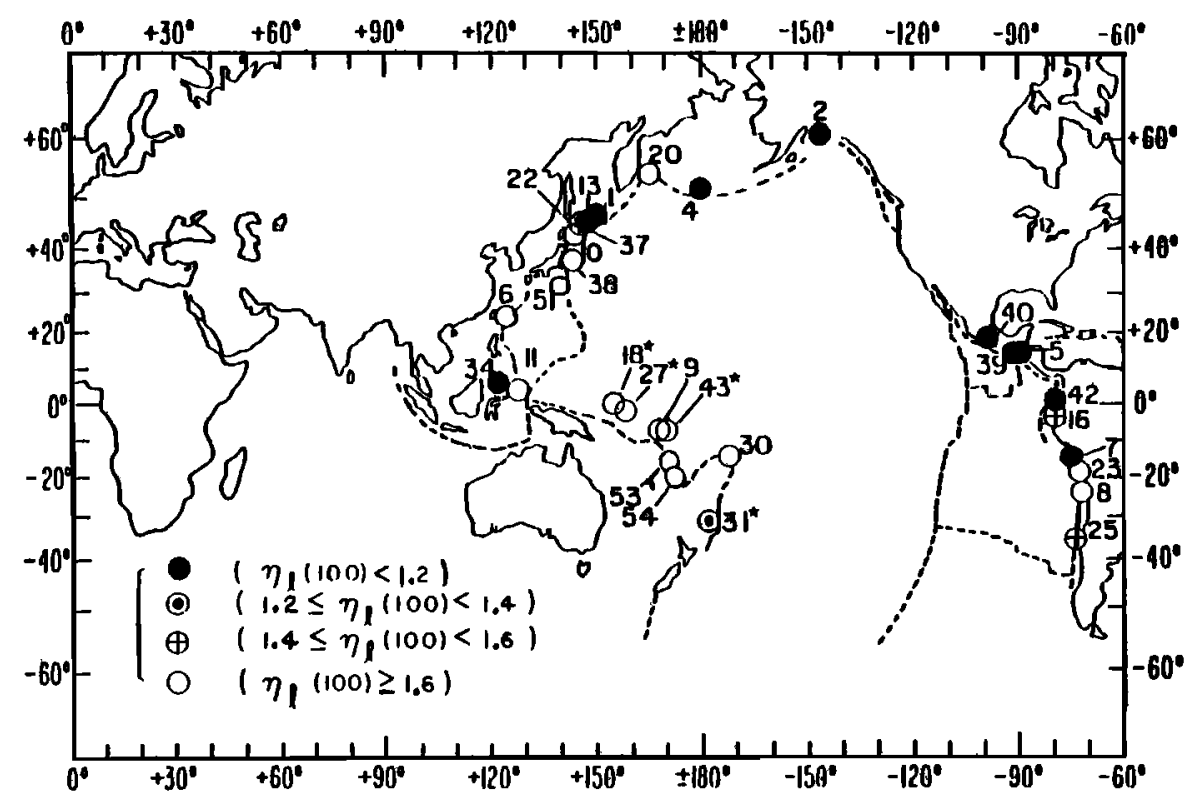

Fig. 2. One-hundred day linear expansion ratios $\eta_{\ell}(100)$. Here, $\eta_{\ell}(100)$ is calculated as the ratio of the one-hundred day maximum linear dimension to the corresponding one-day linear dimension. The symbols are explained in the figure. The number beside each symbol corresponds to the event number in Table 1 . The number with the small star indicates the first event of doublet.

show much expansion. This suggests that, if the second event of the doublet did not occur, the expansion of the aftershock area of the first event would have been slight.

From the New Hebrides to the Tonga-Kermadec regions the aftershock areas expand significantly. For example, the aftershock sequence of the 1980 Loyalty Islands earthquake is shown in Figure 1c. The expansion patterns are similar to those observed in the Ryukyu and the Philippine regions.

Along the Middle American trench the aftershock areas expand very little (Figure 1d). The narrow widths of the aftershock areas $(\lesssim 100 \mathrm{~km})$ and low background activity are characteristic of this region. This observation and other seufce studies (Singh et al., 1984) suggest that the rupture zones are small and have a distinct characteristic size.

The observed expansion patterns vary along the South American subduction zone. The aftershock areas of the December 1970 Peru and the 1975 Southern Chile earthquakes are relatively simple in shape and show little expansion after the one-hundred day period. The patterns of the other four earthquakes listed in Table 1 are complex.

\section{Discussion and Conclusions}

The observed expansion patterns are summarized in Figture 2, which shows the one-hundred day linear expansion ratio $\eta_{2}(100)$ plotted at the respective main shock epicenter. Here $\eta_{l}(t)$ is defined by the ratio of the maximum linear dimension of an aftershock area observed at $t$ days after the mainshock to that of the one-day aftershock area. We notice a distinct regional variation of the expansion ratios. In the western Pacific subduction zones that include northeastern Japan, Ryukyu, the Philippines, Solomon Islands, New Hebrides, and Tonga, the expansion ratios are generally large. On the other hand, in the northern Pacific subduction zones, and along the Middle America trench the ratios are generally small. In the South American subduction zone, the expansion ratios vary from event to event.

These regional variations are strongly correlated with the tectoric enviromments. Uyeda and Kanamori (1979) classified subduction zones according to the strength of interplate coupling, with Chile and the Marianas representing the strongly and weakly coupled zones respectively. In general the subduction zones of the "Mariana" type have large expansion ratios, and those of

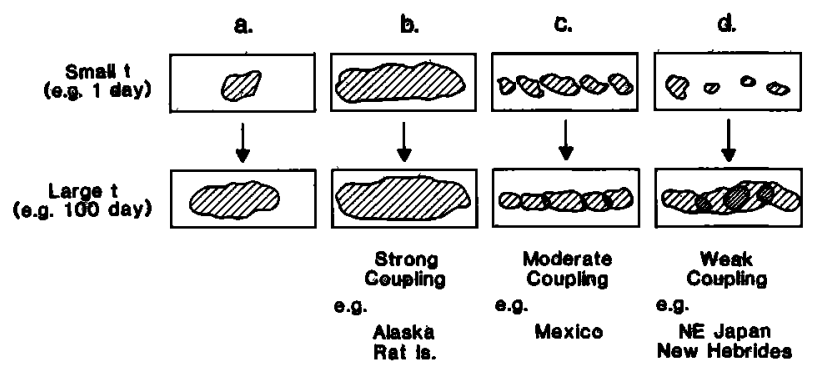

Fig. 3. Schematic figure showing typical expansion patterns of aftershock area. The hatched areas indicate aftershock areas. The aftershock areas at small $t$ (time) is identified as an asperity on a fault zone. a) A typical expansion pattern. The aftershock area expands from the asperity to the surrounding weak zone. b) A fault zone with a uniform, large asperity. The aftershock area does not expand and interplate coupling is strong. c) Densely distributed small asperities. The aftershock zone expands little, and interplate coupling is moderate. d) Sparsely distributed small asperities. An aftershock area expands significantly, often overlapping with that of the adjacent event. Interplate coupling is weak. 
the "Chilean" type have small expansion ratios. Some complexities to this pattern are apparent such as event No. 25 which occurred in south Chile where interplate coupling is considered strong, yet it shows considerable expansion. This event, however, is not in the rupture zone of the 1960 Great Chilean earthquake from which the strong interplate coupling is inferred. Some earthquakes that occurred in the areas of complex bathymetry such as aseismic ridges also have large expansion ratios (e.g. 1968 Molucca Sea, 1971 Kamchatka, 1974 Peru, etc.; Tajima and McCabe, in preparation, 1985).

These results can be explained in terms of an asperity model of fault zones, as illustrated by Figure 3. In this model, a fault zone is modelled by a distribution of asperities and weaker zones (Kanamori, 1978; Lay and Kanamori, 1981). The rupture during the main shock mostly involves asperities. After the main rupture is completed, the stress change caused by the main shock gradually propagates outward into the surrounding weak zones. This stress propagation manifests itself as expansion of aftershock activity (Figure 3a). In this simple model, if the fault zone is represented by large asperities abutting each other (e.g. "Chilean" type), little expansion of aftershock activity would occur (Figure 3b). If the average size of asperities is relatively small, then the strength of interplate coupling is moderate. If these asperities are densely distributed and separated by small weaker zones, no extensive aftershock expansion is expected (Figure 3c). The Mexican subduction zone is a typical example of this type. On the other hand, if smaller asperities are sparsely distributed (e.g. "Mariana" type), large expansion ratio is to be expected and the aftershock areas of adjacent events may overlap each other (Northeastern Japan, Philippine, New Hebrides, and Tonga-Kermadec; Figure 3d).

The actual distribution of asperities is likely to be more complex than the three examples shown in Figure 3. However, we expect that the expansion ratio is in general proportional to the spatial ratio of the total asperity area to the total fault area (asperities plus weak zones).

This picture is generally consistent with that inferred from the distribution of large earthquakes in subduction zones. The subduction zones in Alaska, the Aleutians, the northern Kurile Islands, and southern Chile have experienced great earthquakes $(M>8.5)$, while those along the Tonga-Kermadec, New Hebrides, and Northeast Japan are deficient in such great earthquakes. Thus the expansion pattern of aftershock areas provides clues to the nature of fault zone heterogeneities that control the subduction zone seismicity.

Acknowledgements. We thank Steven Wesnousky, Chris Sanders, Larry Ruff, and Luciana Astiz for critical comments on the manuscript. This research was partially supported by NSF Grants EAR 81-16023 and EAR8312890 and USGS contract \#14-08-001-G-979. Contribution 620, Institute for Geophysics, University of Texas at Austin; and contribution 4215, Division of Geological and Planetary Sciences, California Institute of Technology, Pasadena, California.

\section{References}

Beck, S. L., and L. J. Ruff, The rupture process of the great 1979 Colombian earthquake: evidence for the asperity model, J. Geophys. Res., 89, 9281-9291, 1984.

Kanamori, H., The Alaska earthquake of 1964: radiation of long-period surface waves and source mechanism. I. Geophys. Res., 75, 5029-5040, 1970.

Kanamori, H., Use of seismic radiation to infer source parameters, Proc. of Conference III: Fault mechanics and its relation to earthquake prediction. U.S. Geological Survey Open-File Report 78-380, pp. 283-317, 1978.

Lay, T., and H. Kanamori, Earthquake doublets in the Solomon Islands, Phys. Earth Planet. Int., 21, 283-304, 1980.

Lay, T., and H. Kanamori, An asperity model of great earthquake sequences, Proc. of Maurice Ewing Series, V. 4 Earthquake Prediction A.G.U., 579-592, 1981.

Mogi, K., Sequential occurrences of recent great earthquakes. J. Phys. Earth, 16, 30-36, 1968.

Mogi, K., Some features of recent seismic activity in and near Japan, (2) Activity before and after great earthquakes. Bull. Earth Res. Inst., 47, 395-417, 1969.

Mori, J., Short and long period subevents of the 4 February 1965 Rat Islands earthquake, Bull. Seism. Soc. Am., 74, 1331-1347, 1984.

Omori, F. Investigation of aftershocks, Rep. Earthq. Inv. Comm., 2, 103-139, 1894.

Ruff, L., and H. Kanamori, The rupture process and asperity distribution of three great earthquakes from long-period diffracted P-waves. Phys. Earth Planet. Int., 31, 202-230, 1983.

Schwartz, S. Y., and L. Ruff, The rupture process of the 1968 Tokachi-Oki and the 1969 Kurile Islands earthquakes: support for the asperity model of large earthquake occurrence, EOS Trans., 65, 235, 1984.

Singh, S. K., T. Dominguez, R. Castro, and $M$. Rodriguez, P-waveform of large, shallow earthquakes along the Mexican subduction zone, Bull. Seism. Soc. Amer., 74, 2135-2156, 1984.

Tajima, F., and H. Kanamori, Global variation of expansion patterns of aftershock area. EOS Trans., 62, 949, 1981.

Tajima, F., and H. Kanamori, Global survey of aftershock area expansion patterns. Phys. Earth Planet. Int., in press, 1985.

Uyeda, S. and H. Kanamori, Back-arc opening and the mode of subduction. I. Geophys. Res., 84, 1049-1061, 1979.

Vidale, J. and H. Kanamori, The October 1980 earthquake sequence near New Hebrides, Geophys. Res. Lett., 10, 1137-1140, 1983.

Wu, F. T., and H. Kanamori, Source mechanisms of February 4, 1965 Rat Island earthquake. J. Geophys. Res., 78, 6082-6092, 1973.

(Received April 9, 1985; accepted April 23, 1985) 